\title{
Resposta de VARJÃo (Parkia multijuga) A Subdoses de GlyPhOSATE
}

\author{
Response of Varjão (Parkia multijuga) Seedlings to Reduced Glyphosate Rates
}

\author{
YAMASHITA, O.M. ${ }^{2}$, VIEIRA, R.G. ${ }^{3}$, SANTI, A. ${ }^{4}$, RONDON NETO, R.M..$^{5}$ e \\ ALBERGUINI, S.E. ${ }^{6}$
}

\begin{abstract}
RESUMO - O consumo de madeira no Brasil e no mundo apresenta demanda crescente. Em confronto com a pressão ambientalista de manutenção das florestas nativas, há necessidade de se estabelecerem áreas de reflorestamento para suprir o aumento da demanda de madeira, com a utilização de formas de manejo e tratos culturais que permitam o pleno crescimento das essências florestais. Um dos principais problemas do manejo de reflorestamento é a interferência das plantas daninhas após o plantio das mudas no campo, sendo o uso de herbicidas a principal forma de manejo. Este trabalho teve o objetivo de avaliar a eficiência de doses crescentes de glyphosate em mudas de varjão em condições de ambiente protegido. Foram avaliadas as doses de 0, 90, 180, 360 e $720 \mathrm{~g} \mathrm{ha}^{-1}$ de glyphosate em plantas com quatro meses de idade, observando a intoxicação das plantas, altura, diâmetro do caule e número de folhas. O varjão, nas condições do experimento, apresentou tolerância e recuperação ao glyphosate até a dose de $360 \mathrm{~g} \mathrm{ha}^{-1}$. Doses superiores a esta retardaram o crescimento da planta. O prejuízo causado pela deriva de glyphosate nessas plantas foi diretamente proporcional ao aumento da dose. Os sintomas evoluíram para queda de folhas, comprometendo o crescimento das plantas.
\end{abstract}

Palavras-chave: herbicida, floresta, subdose, fitotoxicidade.

\begin{abstract}
Wood consumption has significantly increased in Brazil and worldwide.The environmental pressure to preserve native forest led to the need to establish reforestation areas to meet the increasing wood demand by applying cultural practices and management allowing a total growth of forest trees. One of the main problems in reforestation management is weed competition after seedling planting, with herbicide use being the main form of management. The objective of this work was to evaluate the phytotoxic effect of increasing rates of glyphosate on Varjão seedlings, under greenhouse conditions. Concentrations of 90, 180, 360 and $720 \mathrm{~g} \mathrm{ha}^{1}$ of glyphosate were evaluated in four-month-old plants by observing plant toxicity, plant height, stem diameter, and leaf number. A control was also used without herbicide application to compare the effects. Under the conditions of this experiment, Varjão presented tolerance to and ability to recover from glyphosate up to the rate of $360 \mathrm{~g} \mathrm{ha}^{-1}$. Higher rates delayed plant development. The damage caused by glyphosate drift in these plants was directly proportional to rate increase. The symptoms included leaf fall, compromising plant growth.
\end{abstract}

Keywords: herbicide, forest, reduced rate, phytotoxicity.

1 Recebido para publicação em 14.2.2006 e na forma revisada em 4.8.2006.

2 Eng.-Agrônomo, M.S., Doutorando em Agricultura Tropical pela FAMEV/UFMT, Professor do Departamento de Agronomia da Universidade do Estado de Mato Grosso - UNEMAT, Caixa Postal 324, 78580-000 Alta Floresta-MT, <yama@unemat.br>; ${ }^{3}$ Acadêmico do Curso de Engenharia Florestal - UNEMAT/PCAA, <rogoviflorestal@unemat.br>; ${ }^{4}$ Eng.-Agrônomo M.S., Professor do Departamento de Agronomia - UNEMAT/PCAA, < adalbertosanti@ unemat.br>; ${ }^{5}$ Eng. Florestal D.S., Professor do Departamento de Engenharia Florestal - UNEMAT/PCAA, <rubensrondon@yahoo.com.br>. ${ }^{6}$ Acadêmica do Curso de Administração da União das Faculdades de Alta Floresta - UNIFLOR, Av. T, s/n, 78580-000 Alta Floresta-MT, <miyaf10@hotmail.com.br>.

Planta Daninha, Viçosa-MG, v. 24, n. 3, p. 527-531, 2006 


\section{INTRODUÇÃO}

O reflorestamento no Brasil vem apresentando merecido destaque, dada a necessidade do consumo cada vez maior de madeira para inúmeros fins, sem que haja, ainda, substituição por produtos alternativos.

Dentre as espécies cultivadas para esse fim, destaca-se o varjão (Parkia mutijuga) que apresenta características como maciez ao corte, madeira muito leve e textura grossa (Lorenzi, 2002).

Para atender à crescente demanda de madeira, é necessário que as áreas de reflorestamento sejam conduzidas visando a produção em larga escala e em pouco tempo. Para isso, a prática de tratos culturais que inibam ou reduzam os fatores limitantes ao crescimento das plantas deve ser levada em consideração desde o início da atividade (Pitelli \& Marchi, 1991).

A interferência de plantas daninhas é um desses fatores que reduzem o crescimento das plantas; a utilização de herbicidas diminui esses efeitos, razão pela qual eles são sempre usados em áreas de reflorestamento, dada a sua alta eficiência e rendimento, além da economia (Silva et al., 2000).

O glyphosate é um dos herbicidas mais utilizados em áreas de reflorestamento, devido ao efetivo controle de plantas daninhas (Christoffoleti et al., 1998; Kogan \& Figueiroa, 1999; Venegas \& Palazuelos, 1999). Por ser não-seletivo e de amplo espectro de ação (Rodrigues \& Almeida, 2005), é usado, em jato dirigido, nas áreas de cultivo de eucalipto e pinus (Tuffi Santos et al., 2006).

No entanto, como qualquer outro herbicida, o glyphosate pode sofrer deriva, atingindo plantas que não eram alvo da aplicação, provocando injúrias e até a sua morte.

Muitos trabalhos com herbicida vêm sendo desenvolvidos, visando avaliar a intoxicação das plantas com glyphosate em pinus (Silva et al., 2000; Queiroz et al., 2002) e eucalipto (Silva et al., 1994; Tuffi Santos et al., 2006), mas ainda não há pesquisas com outras espécies florestais, como o varjão.

Este trabalho teve o objetivo de avaliar o efeito de doses crescentes de glyphosate em mudas de varjão em condições de ambiente protegido.

\section{MATERIAL E MÉTODOS}

Este ensaio foi conduzido em viveiro com tela de retenção de luminosidade de $50 \%$ nas laterais e na face superior, nas dependências do viveiro de mudas da CEPLAC, no município de Alta Floresta-MT, no período compreendido entre agosto de 2005 e fevereiro de 2006.

As mudas de varjão foram produzidas em tubetes que continham $80 \%$ de composto orgânico e $20 \%$ de moinha de carvão, na própria CEPLAC. Dois meses depois de semeadas, as plantas jovens foram transplantadas para vasos de polietileno com capacidade para 3,5 L de substrato. Foi utilizado o Latossolo Vermelho Distrófico, que apresentou textura areno-argilosa e pH 6,8, coletado em área de barranco. O substrato foi peneirado e a fertilidade corrigida, utilizando-se a formulação 04-26-14 + micronutrientes, no momento do transplante das mudas.

Foi adotado o delineamento experimental inteiramente casualizado, com quatro repetições. Cada unidade experimental foi constituída de uma planta por vaso.

As plantas foram irrigadas diariamente, o suficiente para repor a perda de água. As mudas com dois meses de transplante foram tratadas com quatro subdoses de glyphosate: $6,25,12,5,25$ e $50 \%$ da dose recomendada de $1.440 \mathrm{~g} \mathrm{ha}^{-1}$ do equivalente ácido de glyphosate $\left(0,90,180,360\right.$ e $720 \mathrm{~g} \mathrm{ha}^{-1}$ do i.a. de sal de isopropilamina, respectivamente). No momento da aplicação, as mudas apresentavam de 6 a 8 folhas compostas e média de $44 \mathrm{~cm}$ de altura.

O herbicida foi aplicado nas plantas por meio de um pulverizador costal, pressurizado a $\mathrm{CO}_{2}$, mantido em pressão constante de $30 \mathrm{Lbf} \mathrm{pol}^{2}$, portando barra com um bico, munido de ponta de jato plano APG 110.02, com gasto de calda de $300 \mathrm{~L} \mathrm{ha}^{-1}$. No momento da aplicação a temperatura ambiente era de $29{ }^{\circ} \mathrm{C}$, com umidade relativa do ar em torno de $75 \%$, nebulosidade de $30 \%$ e ausência de ventos.

Foram avaliadas as seguintes características: intoxicação das plantas, através de avaliação visual, adotando-se para isso escala 
de notas que variavam de $0 \%$ para nenhum sintoma visível até $100 \%$ para a morte da planta; número de folhas; e diâmetro do caule. As notas de toxicidade foram tomadas aos 7 , $14,21,28,35,42$ e 49 dias após a aplicação do herbicida. Ao final do experimento realizouse a avaliação da altura de planta, tomada do colo até o ápice do meristema apical; foi contado o número de folhas compostas e medido o diâmetro do caule, a $2 \mathrm{~cm}$ do colo da planta.

Os dados coletados foram submetidos à análise de variância, comparando-se as médias pelo teste de Tukey a $5 \%$ de probabilidade. A variável altura foi ajustada à equação de regressão.

\section{RESULTADOS E DISCUSSÃO}

A toxicidade foi influenciada pelas doses de glyphosate $(p<0,05)$ em todas as avaliações (Figura 1).

Os sintomas visuais de intoxicação das plantas de varjão caracterizaram-se pelo amarelecimento progressivo e mais intenso das folhas compostas a partir da dose de $90 \mathrm{~g} \mathrm{ha}^{-1}$ do i.a. O amarelecimento das folhas foi seguido da queda dos folíolos e aumentava com a dose do herbicida.

O amarelecimento do tecido foliar - também observado por Tuffi Santos et al. (2006) em eucalipto, Miller et al. (2004) e Yamashita \& Guimarães (2005) em algodão, Magalhães et al. (2001a) em milho e Magalhães et al. (2001b) em sorgo - pode estar relacionado com a degradação dos cloroplastos em plantas tratadas com glyphosate (Campbell et al., 1976). Injúrias visuais provocadas por herbicidas podem ser compostas por retardo no crescimento, amarelecimento ou descoloração e redução no estande de plantas (Frans et al., 1986; Thomas et al., 2005).

De modo geral, a intoxicação aumentou gradualmente até os 28 DAA (dias após a aplicação), decaindo nas avaliações seguintes, exceto para a maior dose, em que a intoxicação aumentou progressivamente até os 42 dias, havendo estabilização no momento da última avaliação (49 DAA).

Deriva simulada de $360 \mathrm{~g} \mathrm{ha}^{-1}$ de glyphosate provocou injúrias cujo percentual não superou $17 \%$, decrescendo à medida que as doses eram reduzidas. Tuffi Santos et al. (2004), trabalhando com eucalipto, observaram que $360 \mathrm{~g}^{\text {ha }}{ }^{-1}$ de glyphosate foram suficientes para provocar severas injúrias na parte aérea das plantas.

O maior grau de toxicidade foi verificado com o tratamento na maior concentração de glyphosate $\left(720 \mathrm{~g} \mathrm{ha}^{-1}\right)$; os danos foram altamente significativos, sendo constatada, visualmente, uma injúria de $75 \%$ na avaliação final.

Em todas as doses testadas, exceto $720 \mathrm{~g} \mathrm{ha}^{-1}$ de glyphosate, as plantas apresentaram recuperação gradual, que poderia resultar em total desaparecimento dos sintomas causados pelo herbicida em avaliações futuras.

A altura de planta foi influenciada pelas doses de glyphosate $(\mathrm{p}<0,05)$. Na Figura 2 é apresentada a equação de regressão das doses aplicadas sobre as plantas de varjão. Observou-se redução gradual à medida que as doses do herbicida eram aumentadas. Tuffi Santos et al. (2006) observaram redução no crescimento de eucalipto quando da aplicação de concentrações de $24 \%$ da dose de glyphosate (360 $\mathrm{g} \mathrm{ha}^{-1}$ ).

Na menor dose, a redução de crescimento atingiu 5\% da altura das plantas não-tratadas com o herbicida; na maior dose, essa diminuição foi de $22 \%$ da altura, em relação ao tratamento testemunha. Essa diferença compromete o crescimento normal das plantas, o que, em condições de campo, pode provocar o atraso no processo de corte no momento da colheita florestal.

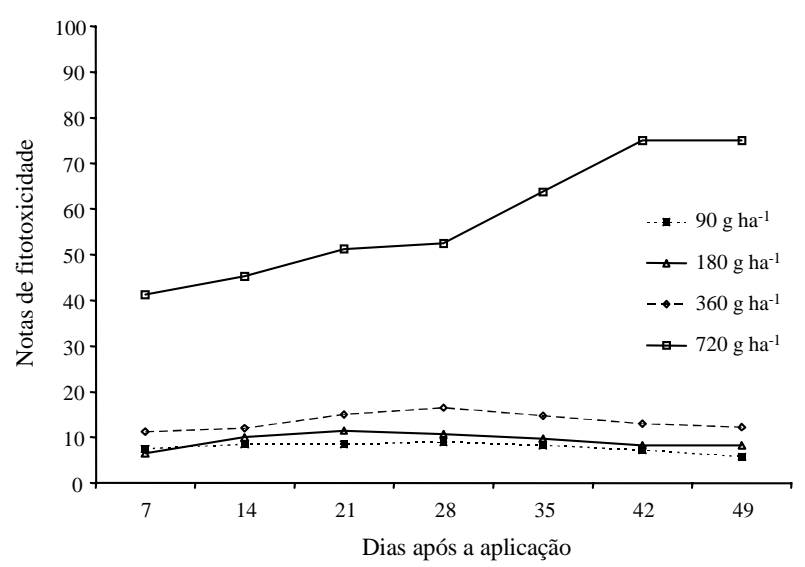

Figura 1 - Notas de intoxicação de plantas de varjão (Parkia multijuga) submetidas a doses de glyphosate. Alta FlorestaMT, 2006. 
Na Tabela 1 são apresentados os valores de altura, diâmetro do caule e número de folhas por planta aos 49 DAA. Não houve diferença significativa no diâmetro do caule das plantas submetidas à aplicação de glyphosate.

Quanto ao número de folhas por planta, não se observou diferença significativa entre os tratamentos, exceto a testemunha $(p<0,05)$, que foi superior aos demais. Apesar da visual diferença da testemunha em relação aos outros tratamentos, as plantas com $720 \mathrm{~g} \mathrm{ha}^{-1} \mathrm{de}$ glyphosate apresentaram 30\% menos folhas que a média das plantas dos demais tratamentos. O efeito das demais doses apresentou número médio de cinco folhas por planta na última avaliação.

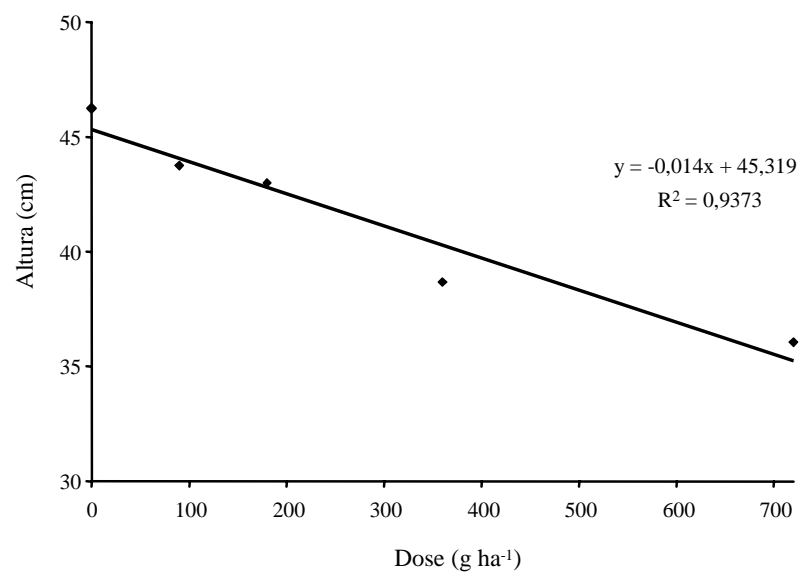

Figura 2 - Redução na altura de plantas de varjão (Parkia multijuga) submetidas a doses de glyphosate após 49 dias da aplicação. Alta Floresta-MT, 2006.

Tabela 1 - Médias de altura, diâmetro e número de folhas de plantas de varjão (Parkia multijuga) submetidas a doses de glyphosate após 49 dias de aplicação. Alta Floresta-MT, 2006

\begin{tabular}{|c|c|c|c|}
\hline Dose $\left(\mathrm{g} \mathrm{ha}^{-1}\right)$ & Altura & Diâmetro & $\begin{array}{c}\text { Número de } \\
\text { folhas }\end{array}$ \\
\hline 0 & $46,250 \mathrm{a}$ & $1,250 \mathrm{a}$ & $8,3 \mathrm{a}$ \\
\hline 90 & $43,750 \mathrm{ab}$ & $1,150 \mathrm{a}$ & $5,0 \mathrm{~b}$ \\
\hline 180 & $43,000 \mathrm{ab}$ & $1,253 \mathrm{a}$ & $5,0 \mathrm{~b}$ \\
\hline 360 & $38,675 \mathrm{bc}$ & $1,045 \mathrm{a}$ & $5,0 \mathrm{~b}$ \\
\hline 720 & $36,050 \mathrm{c}$ & $1,125 \mathrm{a}$ & $3,5 \mathrm{~b}$ \\
\hline $\mathrm{CV}(\%)$ & 6,69 & 9,77 & 24,84 \\
\hline
\end{tabular}

Médias seguidas de mesma letra nas colunas não diferem entre si pelo teste de Tukey a 5\% de probabilidade.
O varjão é uma espécie que, nas condições do experimento, apresentou tolerância e recuperação ao glyphosate até a dose de $360 \mathrm{~g} \mathrm{ha}^{-1}$. Doses superiores a esta podem reduzir o crescimento da planta.

O prejuízo causado pela deriva de glyphosate nessas plantas foi diretamente proporcional ao aumento da dose. Os sintomas evoluem para queda de folhas, comprometendo o crescimento normal das plantas.

\section{LITERATURA CITADA}

CAMPBELL, W. F.; EVANS, J. O.; REED, F. C. Effect of glyphosate on chloroplast ultrastructure of quarck grass mesoplhyll cell. Weed Sci., v. 24, p. 22-25, 1976.

CHRISTOFFOLETI, P. J. et al. Controle de plantas daninhas em Pinus taeda através do herbicida imazapyr. Piracicaba: Instituto de Pesquisas e Estudos Florestais, 1998. 11 p. (Circular Técnica, 187).

FRANS, R. et al. Experimental design and techniques for measuring and analyzing plant responses to weed control practices. In: CAMPER, D. (Ed.). Research methods in weed science. 3.ed. Champaign: Southern Weed Science Society, 1986. $37 \mathrm{p}$.

KOGAN, M.; FIGUEROA, R. Interferência producida por las malezas durante los dos primeros años em Pinus radiata D.Don. R. Bosque, v. 20, n. 1, p. 57-64, 1999.

LORENZI, H. Árvores Brasileiras: manual de identificação e cultivo de plantas arbóreas no Brasil. 4.ed. Nova Odessa: Instituto Plantarum, 2002. v. 1. p. 199.

MAGALHÃES, P. C. et al. Efeito de doses reduzidas de glyphosate e paraquat simulando deriva na cultura do milho. Planta Daninha, v. 19, n. 2, p. 247-253, 2001a.

MAGALHÃES, P. C. et al. Efeito de doses reduzidas de glyphosate e paraquat simulando deriva na cultura do sorgo. Planta Daninha, v. 19, n. 2, p. 255-262, 2001b.

MILLER, D. K. et al. Response of non glyphosate resistant cotton to reduced rates of glyphosate. Weed Sci., v. 52, p. 178-182, 2004.

PITELLI, R.; MARCHI, S. R. Interferência das plantas daninhas nas áreas de reflorestamento. In: SEMINÁRIO TÉCNICO SOBRE PLANTAS DANINHAS E USO DE HERBICIDAS EM REFLORESTAMENTO, 3., 1991, Belo Horizonte. Anais... Belo Horizonte: 1991. p. 110-123.

RODRIGUES, B. N.; ALMEIDA, F. S. Guia de herbicidas. 5.ed. Londrina: Edição dos autores, 2005. 648 p. 
SILVA, W.; FERREIRA, L. R.; MELO, H. B. Tolerância de cinco espécies de Pinus a herbicidas. R. Árvore, v. 24, n. 1, p. 21-25, 2000.

SILVA, W. et al. Tolerância de Eucalyptus spp. a diferentes herbicidas. R. Árvore, v. 18, n. 3, p. 287-300, 1994.

THOMAS, W. E. et al. Yield and physiological response of nontransgenic cotton to simulated glyphosate drift. Weed Technol., v. 19, p. 35-42, 2005.
TUFFI SANTOS, L. D. et al. Intoxicação da espécie de eucalipto submetido a deriva do glyphosate. Planta Daninha, v. 24, n. 2, p. 359-364, 2006.

VENEGAS, R.; PALAZUELOS, R. Control químico de malezas arbustivas y arbóreas en plantaciones de Pinus radiata D. Don. R. Bosque, v. 20, n. 1, p. 79-88, 1999.

YAMASHITA, O. M.; GUIMARÃES, S. C. Resposta de cultivares de algodoeiro a subdoses de glyphosate. Planta Daninha, v. 23, n. 4, p. 627-633, 2005. 